\title{
Contest, contradiction, and security: The moral possibilities of liminal education
}

\author{
James C. Conroy · Doret J. de Ruyter
}

Published online: 13 March 2008

(C) The Author(s) 2008

\begin{abstract}
The article develops a conception of education that we have named liminal education. Liminal education tries to counter the centripetal tendencies of the centre (particular that of the consumer market) by disclosing alternative positions in order to enable children to cultivate a critically reflective disposition. A second feature of liminal education is that it carries the potential to assist children in recognising that otherness is not the same thing as being alien. Finally, it is characterised by an embodiment of the notion of 'communitas', a state in which no one can have authority over another or see themselves as superior. For children who live within the dominant (centre) culture and who find security in consumerism, liminal education is important because it offers them imaginative possibilities which could give rise to alternative conceptions of the good life. Children in liminal communities will benefit from liminal education, because they will have a better understanding of their own position and those of others, which, we believe, will reduce the anxiety of loosing one's identity and thereby the need to return to anxiously held foundational beliefs.
\end{abstract}

Keywords Border pedagogy $\cdot$ Consumerism · Diversity $\cdot$ Economy $\cdot$ Fundamentalism Liberal education $\cdot$ Liminal education $\cdot$ Security

Marc Chagall, Over the Town

Marc and Bella

Are happily flying over Vitebsk

-this is a real a shining good

but if you look closely there's a lout

squatting on the mud

J. C. Conroy

Faculty of Education, University of Glasgow, St. Andrew's Building, 11 Eldon Street,

Glasgow G3 6NH, Scotland, UK

D. J. de Ruyter $(\bowtie)$

Department of Theory and Research in Education, Faculty of Psychology and Education,

VU University Amsterdam, Van der Boechorststraat 1, 1081 BT Amsterdam, The Netherlands

e-mail: dj.de.ruyter@psy.vu.nl 


\author{
near the fence \\ -like a Brueghel peasant \\ he's laying a turd \\ at the edge of their wedding part \\ ... though many a reproduction \\ mars this famous painting \\ by omitting not just his arse \\ but the entire squatting lout
}

Tom Paulin (1999, p. 19)

\title{
Introduction
}

It is hardly revolutionary to suggest that liberal democracies under the ascendant star of a globalised neo-liberal market ideology have been successful in synchronising their economic and social policies to facilitate the shift from national and multinational to transnational or global corporations (see Conroy 2004; Lingard 2000). But what is becoming increasingly apparent is that the synchronisation has, of late, shifted ground so that the philosophies and practices of public goods, like education, are increasingly to be predicated upon this market philosophy. This is seen most substantially in Anglophone economic cultures and therefore our focus here will be primarily on these cultures. In England and Wales the market philosophy is most visible in the policies of New Labour, which press education to reconfigure itself as an economic rather than an ethical enterprise (see for instance DfES 2004, 2005). Interestingly, there appears to be a dichotomy between the headline claims of aspiration and the more detailed development of objectives in many of these government documents. Whereas the headlines proclaim fealty to general principles of liberal education in the pursuit of human flourishing, the detailed prescriptions deal almost exclusively with the upskilling of human abilities for work and economic performance. This can be illustrated with the No Child Left Behind Act in the US, which was signed in 2002 and the Every Child Matters green paper from 2003 in the UK. More parochially, it is echoed in recent education reports of the Scottish Executive, most especially those around the government drive for Educating for Excellence (2004). These moves represent a trend in government thinking over more than a decade (see DfES 2001) and are illustrated by Learning and Teaching Scotland \& Scottish Executive papers, which, in 2001, claimed that an important aim of education is "a strengthening commitment to ensure for pupils aged 3-18 a continuum of learning that prepares them for the world of work and is based on an inclusive ethos of achievement for all" (DfES 2001, p. 3). This contrasts importantly with the position of former French Prime Minister Jospin, who declared himself in favour of a market economy, but not a market society, observing that "[I]n itself, the market creates neither meaning, nor direction nor project. For us the market-even regulated, even controlled-does not eliminate the need for the social contract. We refuse the commodification of societies" (Mason 2001).

But matters are as always more complicated than may be encapsulated in the simple assertion that ministers and bureaucrats may somehow be failing to discharge their ethical obligations to the community. It would be too easy to suggest that the impulse of politicians to pay obeisance to the global markets and the impulse of the markets to control our behavioural patterns represents an unwelcome hegemonic imposition on the luckless 
citizen. While it may well be true that this economisation of life is indeed imposed it may be equally true, as Ritzer (2000) maintains, that it is also welcomed by many. He argues that one of the reasons for the success of a chain like McDonalds is the fact that it efficient, calculable, predictable and controlled. This success is so complete, that Ritzer has used its name for "the process by which the principles of the fast-food restaurant are coming to dominate more and more sectors of American society as well as of the rest of the world" (p. 1). Further, it might be argued that what McDonalds offers is symbolic security. Its global effect is cultural as much as economic. This makes matters yet more complicated. Applying Ritzer's insights to education, Bottery (2000) opines, that education is "increasingly subjected to the twin demands of rationalisation and commodification ... [which] occurs through the attempt to turn education into a product, its 'consumers' adopting market attitudes, its producers being judged by their performance in this market" (p. 158). McDonaldization offers people a sense of security where their expectations are expressly and consistently met.

The drive for security can sometimes be discovered where it is least expected. A clear or poignant example can be found in the appropriation of the notion of 'cool' by white middle class youth who fail entirely to recognise the origins of the idea and its related practices in the resistance cultures of the descendants of black African American slaves carried into late modernity through jazz and hip-hop. Pountain and Robins (2000) suggest that doubt with regard to employment and cultural insecurity is accommodated by a very particular response. "Cool," they argue, "enables people to live with uncertainty and lowered expectations, by concentrating on present pleasures. In short, when the going gets tough, the Cool go shopping" (p. 164f). These lowered expectations find voice in Paulin's poem which directs us to the mass marketing of an image which is, at best, incomplete and at worst a travesty of the artistic impulse behind the original.

Such reactions may reflect one response to a heightened sense of insecurity. But there is another, seemingly entirely opposite, reaction: fundamentalism. There is no doubt that the events of September 11, 2001 changed the world, hastening a trend, identified by, among others, Marty and Appleby (1991), Giroux (1996, 2004) and Marsden (2006), where a growing feeling of insecurity and anxiety is met by a turn to fundamentalism. While fundamentalists are predominantly pictured as fanatical and militant religious people, who try to impose their faith on others and attempt to grab power over nations, in reality it is a much more multifaceted phenomenon. Its manifestations range from violence to assemblies and proselytising within the limits of the law (Marty and Appleby 1991, p. 814). Moreover, while the most obvious and, it might be suggested, most virulent form is religious, it can also be seen in political and cultural retrenchments (e.g. The Tamil Tigers; a secular mystical nationalism may be considered an originator of the cult of the suicide bomber.) The predilection of the current Russian government to react to the insecurities posed by entry into a market economy by recuperating older forms of autocratic government offers one example of political fundamentalism. However, what is characteristic for all kinds of fundamentalism is the feeling of being endangered or undermined in one's identity by the dominant 'modern' culture. The defence, reaction or opposition consists of returning to some pre-modern conception of a religion or culture, which is perceived to be the absolute truth and followed without questioning (De Ruyter 2001). Hence, the strategy consists primarily in restoring the past rather than participating in the progress and change of modern times. Ehrenreich puts it thus, "As the recently religious say, religion provides rules, a ready-made community, and a sense of belonging to something more lasting than a swirl of consumer culture" (Ehrenreich 1989 in Noddings 1993). 
Although the conditions that restore a sense of security clearly vary, reactions to insecurity are similar in their attachment to the predictable, repeatable, never changing products and effects. The lack of reflection and conscious choosing characteristic of behaviourism and the increased enmassing which so concerned Arendt (1958) are ever present dangers where the very complexity and apparent disorder of late modernity precipitate an overwhelming desire to find or re-establish order (even where no order may actually have existed in the past). Both economic-cultural simplification of differences and choices through unification, and religio-cultural fundamentalism, which rejects differences and choices, undermine the very conditions of a flourishing liberal democracy. They do so precisely because both search for securing sameness rather than accepting otherness.

Of course, unpredictable and constant change maintains insecurity and inadvertently fosters the flight to particular symbols of security. Public life in general and education in schools in particular have been subject to significant and apparently inexorable change: so much so that those educators have increasingly sought the certainty of 'doing what they are told.' It might well be argued that despite occasional protests amongst teachers about professional and intellectual freedom, they have in fact been complicit in the creation of an education provision which is highly structured in its shape and form and heavily regulated in its processes. Yet, paradoxically, education in schools should be an important cultural site for fostering the kinds of contestatory perspectives which are necessary to avoid the flight to faux security. In suggesting this we are cognisant of the limitations of education in schools and do not wish to overstate its power somehow to reverse these societal trends. Children, however, do spend much of their time during their formative years in school, putatively at least in pursuance of an education. No doubt there are many ways in which such conditions of contest may be cultivated. Here we attempt to develop and apply the metaphor of liminality to educational contexts and practices as one way of addressing the need to introduce students to contestation.

\section{Defining liminality}

In his work, "Mycenae Lookout," the poet Seamus Heaney (1996) places a watchman on the edge of the city so that he might report any sighting of the returning Agamemnon to Clytemnestra that she in turn might prepare for his assassination. The Lookout, knowing of Clytemnestra's plan and under an obligation to report to her nevertheless places himself at a remove from her, thereby self-consciously locating himself on the fringe or margins of the metropolitan plot. He also can see outside the metropolis to where Agamemnon comes. For Heaney, the Lookout is indeed a liminal figure. While remaining attached to the centre he is not entirely or exclusively of it. He is liminal because he stands at sufficient distance from the centre; it is this which enables him to stand in a different hermeneutical relationship to Clytemnestra than, say, her courtiers. In turn he can then adopt a different perspective and engage in a different evaluation of the claims of the centre. Such a process of distancing may be applied to both events and the protagonists. As Heaney (1996) goes on to say, "I balance between destiny and dread/And saw it coming, ..." (p. 30). Art can be a liminal activity which, if it is to fulfil its role of redress against the claimed matter of factness of everyday relations as well as "whatever is wrong or exacerbating in the prevailing conditions" (Heaney 1995, p. 1), must position itself on the periphery of public civic life. In the work of the poet the adoption of a liminal position is vital if she is to offer more than an affirmation of existing social, cultural and political conditions and their accompanying frameworks of interrogation/interpretation. 
The OED defines liminality as that which is "of or pertaining to the limen or threshold." In English usage the notion has primarily been psychological, indicating that point of intensity of sensation, which needs to be reached before its effects can be perceived or ascertained. Conceived as a doorway or entrance in a narrow sense, the limen may be reduced to a fixed point of entry and/or exit. More than this, liminal positions are inextricably linked to the notion of boundaries and borders, which may be construed as static entities, their nature and shape normally determined by the centre. To construe the liminal only as a fixed point or border position runs the risk of misrepresenting it as somewhat static, a kind of position that one can occupy on a permanent or semi-permanent basis. This lacks the subtlety necessary for recognising and responding to political, cultural and ethical changes which might emerge from the centre. We wish to argue that a fundamental feature of liminality is its lack of fixity or permanence; it is not and cannot be a fixed space, a fixed point or a fixed set of processes because things are liminal with respect to other things, primarily the centre. So it is that when a particular social, cultural or ethical practice comes to inhabit the centre, the liminal will inevitably change in response. Thus, liminality is flexible and changeable, because it has a relationship with the centre. A practical example may serve to illustrate this. During the 1960's and early 1970's in Britain corporal punishment was regarded as a sine qua non of effective educational practice. This would have been the mainstream or centre position. A teacher who rejected both the principle and the practice of corporal punishment would then have occupied a liminal position with respect to the mainstream or centre. During the 1980's there was a sustained challenge to the claimed educational, social and behavioural efficacy of corporal punishment resulting in its eventually being designated as illegal. Consequently, those who once occupied the liminal position of not agreeing with corporal punishment now find themselves at the centre and those who continue to uphold to the value of corporal punishment, once at the centre, now occupy a liminal position.

While enjoying some relationship to this spatio-temporal conception, the use here draws upon a modified notion of temporality as ritual space and on a nuanced account of sociopsychological dispositions. As we hope to show, these moves enable us to extend the meaning to embrace states of teachers' and pupils' being. In his exploration of the Rites of Passage, Victor Turner $(1969,1995)$ describes modes of being to be found in the liminal state. In the 'normal' state, which he calls the status system, certain rules and regulations, distinctions and social ascriptions, values and attitudes structure the relationship between different groups and individuals. In the liminal state these distinctions are suspended or negated; it is an interstitial condition where the idea of what is normal and abnormal is, however briefly, bracketed out. In this non-state one cannot have authority over another or see themselves as superior- all are equally stripped of their badges, labels and so on. Turner has observed that those in the liminal space find themselves drawn together in bonds of fellowship or 'communitas,' precisely because they have equal status, and therefore no status.

Thus there are two major tropes in our reflections on the liminal. One concerns the shifting and dynamic relationship between the ideological centre and the periphery, the other between particular ways of making sense of being. Within the educational context this conception of liminality can take three forms. First, it could be a description of that time of transition from childhood to adulthood. At a particular stage in their lives, roughly between 12 and 18, adolescents can be regarded as being in a sort of in-between stage. They are no longer children, which is apparent in the increasing self-determination with respect to their rights, but are as yet neither legally nor psychologically adults. For them it is possible to move back and forth, from childhood to adulthood, returning time and again 
to this in-between stage. The second form liminality can take is as a separate space or spaces from those at the centre, for instance, in the position occupied by religiously denominated schooling in a secular society. This refraction of the liminal is societal and differs conceptually from the first which was primarily predicated on the temporal metaphor. In contradistinction this one is spatial. Liminal schools or education are not separate from the centre, for then they would not have a threshold status; on the contrary, they might even want to try to influence the centre, say for example, in how issues of practical justice are to be dealt with in education generally in a liberal democracy, or again on how education for human relations is to be conducted. The third form is that the teacher or teachers can develop pedagogies and dispositions which, while operative within a state education sector, can nonetheless reflect a liminal position. While touching on all three of these, we will give particular emphasis to the last.

\section{Liminal education}

Modern liberal democracies and their institutions are predicated on a belief in ideological contestation as a way of ensuring that a particular hegemony does not emerge, snuffing out alternative views of the purposes of being, living and acting in the process. If liberal democracy and its concomitant protection and nurturing of human flourishing are to be supported and sustained, then it is important that children are introduced to such ideological contestation. This may be justified by the claim that such societies require citizens who respect the rights of others to subscribe to different ideas and ideals from those they hold themselves. Equally, citizens will flourish if they can pursue the ideas and ideals they cherish. Both these characteristics suggest that children need to be familiarised with diverse traditions and cultures (see, for instance, Brighouse 2006). This may be done in many and varied ways and through a variety of media which might include cultural sites such as museums, theatre, graffiti, music and television. Undoubtedly many good teachers have, consciously or unconsciously recognised this need and acted accordingly.

Liminal education represents one positional strategy to counter the tendency of the centre to homogenise and to challenge its centripetal force by revealing with and for children alternative positions critical of, or running counter to, the centre in order to enable them to cultivate a critically reflective disposition themselves. By engaging and exploring insights to be gleaned from the periphery and deployed in their own education, children will enjoy a richer and more varied experience. This, we would argue, offers greater possibilities of children developing an authentically critical perspective as they grow up into an increasingly complex world, which demands ever more subtle judgements of the practical wisdom.

A second feature of liminal education is that it carries the potential to assist children in recognising that otherness, those who are not in the mainstream, is not the same thing as being alien, thus offering them a nuanced account of sameness and alterity. This may be manifest in the recognition of the other as being in quite a different position to that assumed in and/or by the centre. This in turn entails a respect for the right to occupy such liminal positions, though it does not necessarily imply that children are taught to respect the content of the position. Muslim religious and social practices have recently been the subject of a somewhat alarmed educational and political discourse in Europe and the USA. The assumption underpinning this alarm has been that the particular cultural practices entertained by such people are alien and consequently to be rejected. Indeed, reports about and by British Muslims (see, for instance, Ameli et al. 2005) on educational values would 
be considered by many as inimical to the deeply held liberal sensibilities of the political centre and not to be entertained. With their attachment to philosophies of gender difference and doctrines of sexual control, the views of some Muslims seem profoundly at odds with those of mainstream political and social culture. Yet, all European Muslims live and work in the same spaces as indigenous Europeans and, consequently, may not easily be deemed as entirely alien. There are values that, while not directly shared with those of the centre, may nevertheless bear a family resemblance. For all their marginal status we might yet learn something of importance about the relationship between the personal and the social from the apparently marginal claims. Of course, if we deem these conservative views as inadmissible (or little more than the subject of ridicule) in the classroom children are apt to learn little enough about the partial, constructed and possibly temporising nature of their own values. In some important respects, then, such communities occupy a liminal space with respect to the central educational and social culture. And it is precisely this that teachers need to address and that all teachers need to do. Our plea, therefore, for the inclusion of marginal ideas should not be understood as one for separate schools for those on the margins in which only marginal ideas are taught. Liminal education only takes place in situations in which there is interaction between people who are in different position with regard to the inside and the margins. This brings us to the next characteristic.

This third characteristic, which might also be regarded as being the most salient difference between liminal education and the educational conceptions of liberalism and postmodernism (that we will address hereafter) lies in its embodiment of the notion of communitas, which we described in the former section. Turner argued that status consciousness is a significant barrier to the cultivation of communitas in structured social settings. We may think of this in terms of Buber's (1970) I and Thou. This way of being captures the impulse to encounter another self $^{1}$ as one whose being is never entirely captured in categories and classifications, no matter how extensive. Encounter has no other purpose than itself. Buber acknowledges that life in the world of the encounter is not the life of one's everyday transactions-it would be impossible to constantly live such a life since both its intensity and its lack of structure would fail to support some fairly basic features of survival and social engagement. However, he argues that the life of everyday structured existence may be configured in the light of the encounter. Thus, the instantiation of communitas may enable children and teachers from a diversity of backgrounds to explore their differences in equality and allows them to explore other or new views they have not experienced before.

Within liminal education the teacher is envisaged as one who needs to adopt a transitional position between not only childhood and adulthood, but also between the centre and the periphery. The kind of education proposed here is significantly dependent on the teachers' critical dispositions and commitment; crucially it rests upon teachers who can take a liminal position in (respect of) the world. This embraces particular sets of dispositions, attitudes to the self, relationships to power and positions on pedagogy. Some of the following characteristics might serve as example. First, the liminal teacher is one who recognises the need, on occasion, for change and is unafraid to engage in it, but does not change on whim. Second, her perspective is not limited to what is the case but she continually has her antenna out in the search for new and better ideas/practices/formulations whether these be within or beyond her position. Third, she is always prepared to

\footnotetext{
${ }^{1}$ Buber does not limit the 'I-Thou' to person-person encounters only but sees it as extending so to speak downward into nature and upward to the heavens. However for our purposes the emphasis on the human encounter will suffice.
} 
explore new pedagogies where she thinks these might open new vistas. Fourth, liminality gives permission to introduce into the classroom considerations of disruption, chaos, conflict and dark emotions, which are too frequently excised from the discursive practices of education (Carr and Davis 2007). Thus, the teacher may be seen as one who cultivates in herself and the other the life of the imagination. Although schools and classrooms are normally and normatively structured environments, teachers should be sensitive to those liminal moments, configured in the light of communitas, where structure and its embodied norms are suspended in favour of an encounter with others, with a work of art, or with an apprehension of the transcendent. While the normatively structured environment of everyday school life may quickly re-assert itself, nevertheless the life governed by these norms is irrevocably if only imperceptibly influenced by the liminal encounter. Such encounters have become particularly urgent where classrooms across liberal democracies have become increasingly constricted by atelic notions of performance. This has tended to occlude the openness of educational possibility. The teacher who wishes to be more than a technician must try to keep open the liminal spaces.

Liminal education is not possible if the pupils are unwilling or do not engage in the liminal experience. Therefore, it is incumbent on the teacher to understand what features of the experience might be barriers for children, barriers which may range from feelings of false shame/embarrassment to disinterest in either the content or the purpose of the engagement. These are precisely the barriers that liminal education tries to address. The openness of the teacher and the environment cultivated in the classroom to unexpected, serendipitous and liminal eruptions may open up consequent debates and on the relative merits and demerits of grunge and garage, Pullman and Rowling, or Keats and Yeats. However, the aim of liminal education is not primarily to please students but to offer an invitation into the variegation of the world which may be extremely challenging, and which some will dislike and many find difficult.

Liminal education might, at first sight, be seen as a version or extension of Giroux's border pedagogies or as no more than a re-statement of traditional liberal education. Henry Giroux $(1992,1996)$ has made much use of the notion of border pedagogies because they allow us to see the bounded world of education-which for him is still a modernist project - and those alternative bounded spaces which are, so to speak, adjacent to it. These include the bounded spaces which youth inhabit outside the normative structures of the world of the school. He advocates a pedagogy of border crossing which "signals forms of transgression in which existing borders forged in domination can be challenged and redefined... [and] speaks to the need to create pedagogical conditions in which students become border crossers in order to understand otherness in its own terms, and to further create borderlands in which diverse cultural resources allow for the fashioning of new identities within existing configurations of power" (Giroux 1992, p. 28). Giroux's use of the metaphor reflects his desire for a meaningful pedagogy which, in order to develop an extensive vision of the quality of public life, validates and indeed valorises difference. McLaren (1995) has also developed the notion of the borderland as a metaphor for education in late modernity. His purpose is congruent with but more particularly focused than Giroux's in its emphasis on the use of border pedagogy as a method for the liberation from the snares of the dominant corporate consumer culture. Both authors are drawn to the world beyond schooling where youths are not students but consumers, producers, creators, providers of services and so on in a fissiparous, hybridised world, while our conception of liminality is integrated into the life of teacher, student and classroom.

There seem to be three differences between the approach we advocate and that of Giroux and MacLaren. First, they tend to eschew any conception of a literary, cultural and 
epistemological canon. While it is possible to recognise that culture and cultural canons are always in some sense contingent, it is not necessary thereby to evacuate them of a certain kind of transcendent status. Such status relies on an acknowledgement that there are more or less adequate manifestations and interpretations of literature, art, design and architecture, but also of social arrangements, and that considerations about their goodness, adequacy, worthwhileness, and efficacy are not merely arbitrary (see also Raz 2003). Therefore, education should be concerned not only with assisting students to develop their own reading or appreciation, but also with introducing the evaluations of these artefacts and social arrangements that have become recognized as having transcendent status. Centrally, it offers children a complex set of relations, understandings and interpretations that may enable them to become adults in this or that culture. Second, our position takes seriously the liminal status of students themselves. We believe Arendt (1968) was right in warning the adult community not to burden children with their anxieties or responsibilities about how the world is; children should not be turned into full actors in the political arena. Although critical pedagogy does not necessarily expect pupils to be participants in the political domain, there does not seem to be an explicit acknowledgement of the ambiguous position of children. The third difference is related to notions of 'border,' discussed in the former section. Whereas the border metaphor is always prey to the risk of misrepresenting different positions as incontrovertibly either/or with the accompanying sense of the fixedness of things, the liminal can be much more fluent and erupt at different places. It is not constrained by the border in the way that territories on either side of that border are.

Finally, liminal education and liberal education have many similarities, but differ in one fundamental way. Whereas liberal education, most certainly in the heyday of British philosophers of education such as Peters and Hirst, seems to give supreme value to knowledge and intellectual understanding (for instance Peters 1973, p. 240), liminal education actively stimulates children to appreciate that there are several ways of being in the world, like being in awe or wonder, or alternatively crying or laughing with the world. Liminal education therefore does not only consist of critical cognitive reflection on gained knowledge, but also of other forms of learning and appreciating. Although conceptions of liberal education have broadened under the influence of the sometimes astringent evaluations of critical pedagogues, feminist educationalists and communitarians, and even though liberal education has always embraced some sense of the importance of dispositions, it is nonetheless reasonable to suggest that there is little enough attention devoted to other ways of learning than via cognitive reflection.

\section{Liminal education as an adequate response to the two threats to liberal democracies}

Why might we claim that liminal education may offer a resource to ameliorate the excessive threat of uniformity occasioned by the emergence of both market and religious fundamentalisms? In doing so we will try address the two separate but related contexts of the politico-economic centre and liminal (e.g., religious) communities.

While it is true that late industrial market cultures are refracted differently in different polities, nevertheless there is sufficient commonality in the exercise of their domination to suggest that in many liberal democratic polities they have become so powerful that they have undermined plurality. Arguably other forms of governance (oligarchies, traditional kingdoms, or theocracies) may be less conducive to the kind of diversity under consideration but these do not make the claims that liberal democracies make; they do not aim to foster diversity. There are at least two reasons why we should be anxious about the 
dominance of this particular form of global marketisation. ${ }^{2}$ The first is that, in its attachment to the culture of consumption, it offers too singular an account of human flourishing and action (see Arendt 1958). The second is that if indeed the market dominated centre becomes the only option, it closes down the exercise of both epistemic and practical alternatives. This may, in turn, lead to a loss of autonomy and its replacement with heteronomy, which negates liberal democracy and its impulses.

For children who live within the dominant (centre) culture, liminal education is important because it offers them imaginative possibilities which could give rise to alternative conceptions of the good life and of social and cultural relations. This obtains with respect to those features of the common life that lie within the boundaries of the accepted as well as those that are considered strange, awkward or outside accepted norms. For example, liberal democratic governance and the pre-eminence of individual freedoms have been taken as a constitutive good in late industrial liberal democratic polities. Yet it is at least arguable that other forms of governance may produce equally well ordered societies which might be equally or even more conducive to a community's well being. Now, to make such a claim is generally deemed as no more than a foil to make manifest the virtues of our present form of governance. But surely, treating such alternatives seriously may be beneficial with regard to the other who the students may learn to see with different eyes, but also for themselves wherein they can see their own taken-for-granted assumptions as at least worthy of serious scrutiny. This may open up a challenge to students that they turn inwards to look again at what it means to be an individual self in a wider perspective than in one's market value, i.e. being self-assertive, consuming, good looking, high achieving and so on. Such labels, characteristic of the dominant culture, give children what we would call a one-dimensional sense of themselves. Liminal education tries to foster a conception of a person not in terms of what she has or what she looks like, but her sheer being. This being-who-she-is or self is of course multidimensional but is never entirely summed up by the classificatory labels we attach to her. Liminal education addresses this surplus that lies outside market value, thereby allowing pupils to perceive themselves in a way that transcends such labelling.

We have suggested that the liminal education of children in the centre also benefits others. Throughout this article we have tried to show that it encourages children to explore positions of others, which we believe is likely to increase respect for the right of others to entertain contrary positions. This in turn may lead to a decrease in anxiety of those on the border who perceive themselves as being relegated to a space beyond the border and thereby permitted neither to speak their mind nor live according to their ideas and ideals even though they feel a need to retain a connection with the political and cultural centre. Thus, if they wish to reduce the flight into either politico-cultural atrophy or fundamentalism, those at the political centre should not only accommodate, but also encourage the liminal. Liminal education has the potential to reduce the anxiety of losing one's identity and thereby the need to return to anxiously held foundational beliefs.

With respect to minority communities, we believe there are two other reasons why liminal education may be important. First, by adopting the cultural and pedagogical practices of liminal education they might get a better understanding of the liminal nature of their own community as well as of the dominant centre. Instead of teaching in black and white, liminal education assists children in exploring the nuances, the possible similarities and the profound differences between their own community and mainstream society. This

\footnotetext{
${ }^{2}$ We are not suggesting that markets per se have malign effects, merely that the particular late industrial inflection may have.
} 
might reduce their, or at least their parents' and communities', anxieties about being swallowed up or seduced by the dominant culture, because they have a better understanding of this culture and in consequence may cultivate a better defence mechanism to retain their particular (liminal) identity. Second, every community has its central and threshold positions. Communities that are liminal within a society are not necessarily devoid of a centre themselves. Religious communities within secular societies for instance have centrally determined doctrines, practices and regulations and many are more or less centrally led. Liminal education within these communities would include the variety of positions within their own traditions. Even those strong traditional and doctrinally centrist communities such as the Catholic Church have also managed to tolerate the existence of liminal groups who continue to see or regard themselves as being Catholic (Conroy 2004). Thus, Catholic education can be construed as an example of liminal education not only in relation to the societal centre but also, on occasion with regard to its own religious centre.

A particular consequence of a general acceptance and practice of liminal education could exacerbate the threat to liberal democracies. The appetite of governments across a number of Anglophone polities for an expansion of religiously affiliated schooling in the face of the general secularisation of society may seem a welcome shift in public policy to some, but it carries potent dangers for liminal communities themselves. The justification for the existence of religiously denominated schooling must somehow attach itself to a conception of difference, refracted through alternative ontologies and cultural practices. If their distinctiveness were to be occluded by government embrace, then they might be tempted to retreat beyond the borders in order to retain their identity. Conversely, the polity would also lose the very distinctiveness that such educational communities bring to bear on public conversations about human flourishing and its relationship to education itself.

\section{Conclusion}

In this article we have suggested that liminal education offers a potential solution to the flight to the imagined twin repositories of security detailed in our opening section. We believe that by offering liminal education, children will not inexorably drift into a onedimensional consumer identity or some version of fundamentalism. However, since liminal education opens up countervalent visions and options, and fosters contestation, the obvious counterargument would be that it increases feelings of insecurity instead of decreasing them. It might appear as if this proposal has the effect of undermining the sense of security felt by those at the centre precisely because theirs is a mainstream identity. For those in liminal communities it seems to take away the securities with which they were raised. One response to this objection is that liminal education does indeed question children's security; we might even admit that it undermines their security. However, given that it does so in a safe environment, it might very well succeed in its aspiration of assisting pupils in establishing a sense of security rooted in their own being. We believe that such a security is more stable and profound than that which might be founded in an extrinsic attachment. Is this an uncertain undertaking? Yes it is, but not unsafe. Is it a sufficient way to counter the two threats to liberal democracies discussed? That we do not know; that is an empirical question which we have not addressed in this article. There remains much to be done in developing the notion of the liminal as it might apply to the particular social, cultural and pedagogical practices of the classroom and school. We have, however, tried to argue that in theory liminal education has such a potential, acknowledging that school education is only one of the many influences on children. 
Open Access This article is distributed under the terms of the Creative Commons Attribution Noncommercial License which permits any noncommercial use, distribution, and reproduction in any medium, provided the original author(s) and source are credited.

\section{References}

Ameli, S. R., Azam, A., \& Merali, A. (2005). Secular or Islamic? What schools do British Muslims want for their children? (Vol. 3 of the British Muslims' Expectations Series). London: Islamic Human Rights Commission.

Arendt, H. (1958). The human condition. Chicago: Chicago University Press.

Arendt, H. (1968). Between past and future. London: Penguin.

Bottery, M. (2000). Education, policy and ethics. London: Continuum.

Brighouse, H. (2006). On education. London: Routledge.

Buber, M. (1970). I and Thou (trans: Kaufmann, W., Ed.). Edinburgh: T. \& T. Clark.

Carr, D., \& Davis, R. A. (2007). The lure of evil: Exploring moral formation on the dark side of literature and the arts. Journal of Philosophy of Education, 41(1), 95-112.

Conroy, J. C. (2004). Betwixt and between: The liminal imagination, education and democracy. New York: Peter Laing.

De Ruyter, D. J. (2001). Fundamentalist education: A critical analysis. Religious Education, 96(2), 193-210.

DfES. (2001). Education and skills: Delivering results: A strategy to 2006. Available at: http://www.dfes. gov.uk/deliveringresults/docs/DfES_strategy_Document.doc. Accessed 12 Dec 2005.

DfES. (2004). Autumn performance report 2004. Available at: http://www.dfes.gov.uk/deptreport2004/ autumn_performance_report. Accessed 12 Dec 2005.

DfES. (2005). 14-19 Education and skills-White paper. Available at: http://www.dfes.gov.uk/publications/ 14-19educationandskills. Accessed 12 Dec 2005.

Giroux, H. (1992). Border crossings: Cultural workers and the politics of education. New York: Routledge.

Giroux, H. (1996). Slacking off: Border youth and postmodern education. In H. Giroux, C. Lankshear, P. McLaren, \& M. Peters (Eds.), Counter narratives: Cultural studies and critical pedagogies in postmodern spaces (pp. 59-80). London: Routledge.

Giroux, H. (2004). Beyond belief: Religious fundamentalism and cultural politics in the age of George W. Bush. Cultural Studies <=> Critical methodologies, 4(4), 415-425.

Heaney, S. (1995). The redress of poetry: Oxford lectures. London: Faber.

Heaney, S. (1996). The spirit level. London: Faber.

Lingard, B. (2000). It is and it isn't: Vernacular globalisation, educational policy and RE-structuring. In N. Burbules \& C. A. Torres (Eds.), Globalization and education: Critical perspectives (pp. 79-108). New York: Routledge.

Marsden, G. M. (2006). Fundamentalism and American culture (new edition). Oxford: Oxford University Press.

Marty, M. E., \& Appleby, R. S. (1991). Conclusion: An interim report on a hypothetical family. In M. E. Marty \& R. S. Appleby (Eds.), Fundamentalisms observed. The fundamentalist project vol. 1 (pp. 814-842). Chicago: The University of Chicago Press.

Mason, J. (2001). International rescue required. Labour tribune. London.

McLaren, P. (1995). Critical pedagogy and predatory culture. New York: Routledge.

Noddings, N. (1993). Educating for intelligent belief or unbelief. New York: Teachers College Press.

Paulin, T. (1999). The wind dog. London: Faber and Faber.

Peters, R. S. (Ed.). (1973). The philosophy of education. Oxford: Oxford University Press.

Pountain, D., \& Robins, D. (2000). Cool rules: Anatomy of an attitude. London: Reaktion Books.

Raz, J. (2003). The practice of value. Oxford: Oxford University Press.

Ritzer, G. (2000). The McDonaldization of society: New century edition. Thousand Oaks: Pine Forge Press.

Scottish Executive and Learning and Teaching Scotland. (2001). The balance and structure of the curriculum: 5-14 National guidelines. Edinburgh: The Stationery Office.

Scottish Executive Education Department. (2004). The review of the curriculum 3-18. Available at: http://www.scotland.gov.uk/Topics/Education/School-Education/18088/CurriculumReview. Accessed 12 Dec 2005.

Turner, V. (1969, 1995). The ritual process: Structure and anti-structure. New York: Aldine de Gruyter. 